\title{
FOTOGRAFÍA INFRARROJA CON CÁMARAS DIGITALES
}

\section{INFRARED PHOTOGRAPHY WITH DIGITAL CAMERAS}

\section{AUTORES}

Luis Monje Arenas: Licenciado con Grado en Ciencias Biológicas (Universidad de Alcalá de Henares, España, 1987)

luis.monje@uah.es

\section{CURRÍCULUM VITAE}

Licenciado con Grado en Ciencias Biológicas (Universidad de Alcalá de Henares, España, 1987). Técnico Diplomado en Fotografía Científica (Hospital Gregorio Marañón de Madrid, España, 1989). Técnico Superior en Imagen Científica (Universidad de Alcalá de Henares, España). Primer Premio de Investigación de Castilla-La Mancha 1987. Posee varios premios en dibujo y fotografía, entre ellos: el Primer Premio Europeo de Publicidad del Philips 1986, y el Primer Premio de acuarela Caja Madrid, 1985.

\section{RESUMEN}

Hace unos días alguien me preguntó si era posible usar una cámara digital para hacer fotografía infrarroja o, lo que es lo mismo, si los CCD se excitan con el infrarrojo. Pues bien, este fin de semana me he llevado a casa un filtro de gelatina Kodak Wratten N $^{\circ} 87$ que es opaco a la luz visible y permeable al infrarrojo (el filtro es negro) y he tirado una docena de fotografías con resultados más que satisfactorios. 


\section{PALABRAS CLAVE}

Fotografía - Infrarrojo - Cámara

\section{ABSTRACT}

A few days ago someone asked me if it was possible to use a digital camera for infrared photography or, which is, if the CCD are excited by the infrared. Well, this weekend I brought home a gelatin filter Kodak Wratten No. 87 which is opaque to visible light and permeable to infrared (the filter is black) and I threw a dozen photos with more than satisfactory results.

\section{KEY WORDS}

Photography - Infrared - Camera

Hace unos días alguien me preguntó si era posible usar una cámara digital para hacer fotografía infrarroja o, lo que es lo mismo, si los CCD se excitan con el infrarrojo.

Pues bien, este fin de semana me he llevado a casa un filtro de gelatina Kodak Wratten $N^{o} 87$ que es opaco a la luz visible y permeable al infrarrojo (el filtro es negro) y he tirado una docena de fotografías con resultados más que satisfactorios.

Os explico un poquillo como lo he hecho... 
El Wratten 87 es un $10 \%$ permeable a partir de los $750 \mathrm{~nm}$ y aumenta su transmitancia hasta llegar al $80 \%$ a los $850 \mathrm{~nm}$, alcanzando su máximo de $90 \%$ a los $1.100 \mathrm{~nm}$ y prolongándose así hasta al menos la región de los $1.500 \mathrm{~nm}$ (desconozco si la gelatina tiene alguna opacidad más allá de los 1.500 nm, o si el límite lo marca el vidrio del objetivo). Recuerdo que en espectrometría su usaban celdillas de plástico por la opacidad del vidrio ordinario a ciertas zonas del IR.

Hay otros filtros Wratten en la serie 87 (87c, 87b y 87a) que ofrecen su permeabilidad cada vez más lejana del visible.

Podéis ver respectivas sus curvas aquí:

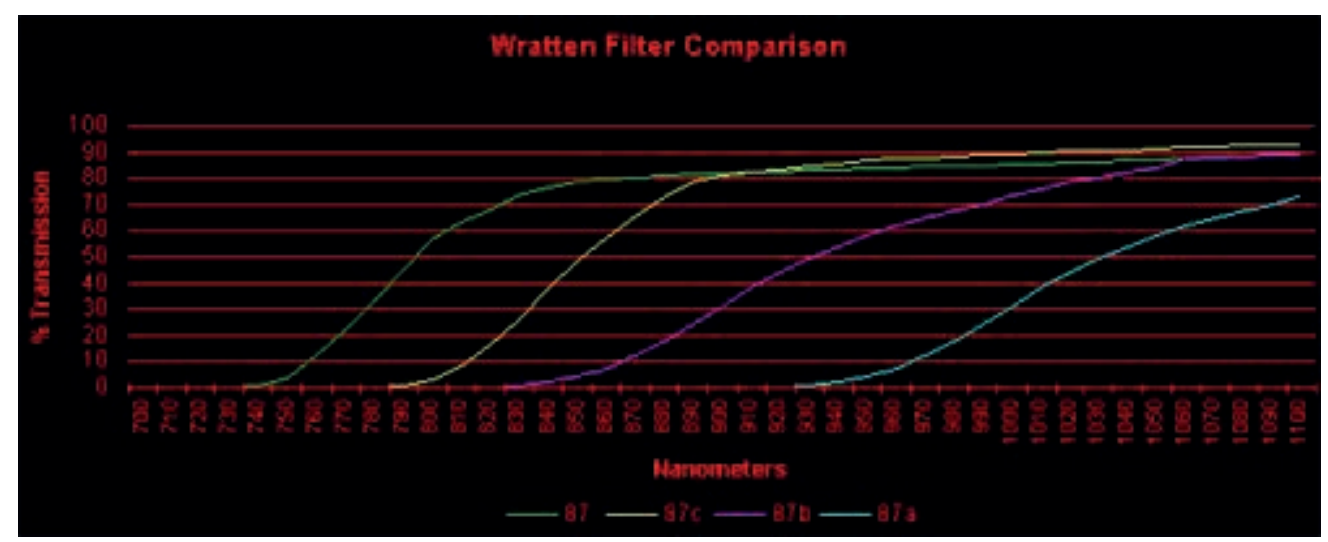

La cámara usada ha sido una Nikon Coolpix 990 montada sobre trípode y con el Wratten sujeto chapuceramente a mano cubriendo el objetivo.

La cámara ha de ajustarse en modo Blanco y Negro ya que, por algún motivo que desconozco, no salen en color, posiblemente hay algún filtro digital de corte que elimina el IR.

Las zonas ideales a fotografiar son las de vegetación espesa y con gran variedad de albedo, ya que vamos a intentar captar lo que estas plantas reflejan y la variedad 
embellece las fotos. Las fotos solo resultan interesantes a pleno sol y tanto mejor si tenemos éste a nuestra espalda.

El mayor problema viene en el enfoque, ya que como recordaréis la luz roja se refracta menos que la media (zona verde-amarilla), lo que da lugar a que la imagen se forme más allá del plano de la película/CCD y, en consecuencia, la imagen salga borrosa y desenfocada.

Podríamos pensar que una solución a esto sería el cerrar mucho el diafragma, para aumentar la profundidad de campo, pero aquí, al igual que en la fotografía tradicional, ocurre un fallo de la ley de no reciprocidad de baja intensidad, peor en versión $C C D$, que se traduce en un notable incremento del ruido electrónico y de la degradación de la imagen. Esto tampoco es mucho problema, por que luego en Photoshop se puede eliminar con el filtro "polvo y rascaduras" que, aunque al profano le suene a noche de parranda y ladillas, puedo asegurar que con un valor 1 ó 2, es bastante efectivo para depurar la imagen.

Otra solución es enfocar en un punto más cercano y congelar el enfoque allí.

Para estimar de forma aproximada cuál es el punto idóneo de enfoque, podéis usar 57 metros para una focal de 50mm o llevaros una SLR con un buen objetivo normal de los antiguos, en que se ve bastante bien la marca de enfoque IR y simular las condiciones de enfoque en dicho objetivo.

En fin, mejor veis los resultados y si algo no ha quedado claro, no dudéis en preguntármelo. 


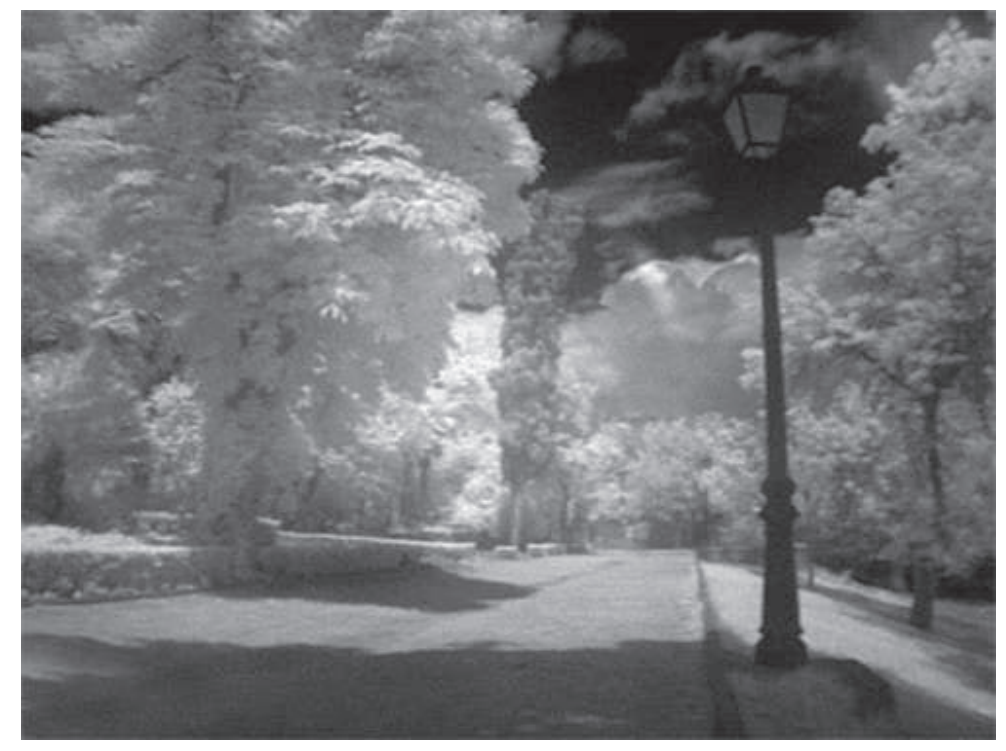

